\title{
OPTIMIZATION OF THERMAL EVAPORATION PROCESS OF GOLD DEPOSITION FOR PEROVSKITE SOLAR CELLS
}

\author{
Kazuhiro Manseki ${ }^{1}$, Mizuki Yamasaki ${ }^{1}$, Norimitsu Yoshida ${ }^{1}$, Takashi Sugiura ${ }^{1}$, Saeid Vafaei ${ }^{2 *}$ \\ ${ }^{1}$ Department of Chemistry and Biomolecular Science, Gifu University, Gifu, Japan. \\ ${ }^{2}$ Bradley University, Mechanical Engineering Department, Peoria, IL, USA.
}

\begin{abstract}
The purpose of this research is to learn how to deposit gold layer for Perovskite solar cell (PSC). PSC was manufactured layer by layer and eventually, a manmade device was used to deposit gold layer as a cathode on hole transport material (HTM), with thermal evaporation technique. An ethanol based nanofluid containing a commercial anatase $\mathrm{TiO}_{2}$ particles with the sizes of around $20 \mathrm{~nm}$ was prepared. A compact $\mathrm{TiO}_{2}$ layer was first spin-coated and subsequently sintered to stabilize particles on FTO glass. In the second step, the anatase $\mathrm{TiO}_{2}$ nanofluid was deposited, using spin coater technique and sintered to form an electron transport layer. The Perovskite and Spiro-OMeTAD as a HTM were successively deposited with a spin-coater in a glove box at a humidity of less than $20 \%$. Regarding the gold evaporation, the distance between source and substrate of the thermal evaporation device was $7 \mathrm{~cm}$. One-step gold deposition was conducted at a pressure of $2 \times 10^{-3} \mathrm{~Pa}$ and the source power was adjusted to form gold layer. It was observed that the deposition condition of gold layer had a significant impact on efficiency of PSC, consisting of FTO glass/buffer layer- $\mathrm{TiO}_{2} /$ nanocrystalline- $^{2}$ $\mathrm{TiO}_{2} /$ Perovskite/Spiro-OMeTAD/Au. Knowing that, this study investigated the effects of deposition, such as the thickness of gold layer on light-to-electricity conversion efficiency of PSC in order to optimize the device performance.
\end{abstract}

KEY WORDS: Thermal Evaporation, Perovskite Solar Cell

\section{INTRODUCTION}

Lead halide perovskite-based solar cells have been extensively studied, owing to their solutionprocessible fabrication and high photon-to-electricity conversion efficiency of over $20 \%$, which is expected to be a low-cost alternative to conventional silicon solar cells [1]. $\mathrm{CH}_{3} \mathrm{NH}_{3} \mathrm{PbX}_{3}$-solar cells (X: I or Br anion) have been for the first time published in 2009 by Kojima et al. [2]. Since then, mesoscopic-type devices i.e. using a porous $\mathrm{TiO}_{2}$ electron extraction layer for depositing the perovskite compound, similar to dye-sensitized solar cells (with dye molecules as light absorbers), have been investigated in order to understand materials interface of the high-efficiency device [3, 4]. In principle, the light absorption of the perovskite layer sandwiched between an electron transporting semiconductor, such as $\mathrm{TiO}_{2}$, and the hole transporting layer, such as 2,2',7,7'-Tetrakis ( $N$, $N$-di-pmethoxyphenylamino)-9,9'-spirobifluorene (Spiro-OMeTAD), enables charge separation in PSC. The photocarriers in these layers can then be moved to each electrode to achieve photoenergy conversion. With regards to counter electrodes, several materials, such as Au and Ag, are the typical choice, often introduced by a thermal evaporation process. In recent years, deposition of carbon pastes has also been examined, aiming to develop low-cost devices [5]. However, a high light-to-electricity conversion efficiency of over $20 \%$ has been achieved only when a metal was vacuum-evaporated as 
a counter electrode so far. This indicates that efficient charge transport can be attained by a suitable materials integration of hole-transport materials and counter electrodes, where thermal evaporation of metals allows hetero-interfaces to form at a molecular level. This process can take advantage of introducing organic semiconductors (hole-transport materials), whose compounds have been demonstrated to be able to produce high fill factors in the device performance. On the other hand, it is known that the metal evaporation process induces penetration of metals into the organic hole conducting layer [6]. Taking into consideration that a hole-transporting film has the thickness of nanometer scale, the metal evaporation condition should be optimized for the device assembly.

In this work, a manmade device was adapted to control thermal evaporation of the Au layer in PSC, where Au was deposited as a cathode on the hole transport material. Some deposition condition of the Au layer was examined, using the PSC consisting of FTO glass/buffer layer$\mathrm{TiO}_{2} /$ nanocrystalline- $\mathrm{TiO}_{2} /$ Perovskite/Spiro-OMeTAD/Au in order to optimize the device performance.

\section{EXPERIMENTAL}

\subsection{Assembly of Perovskite Solar Cell}

We assembled Perovskite solar cell based on the modified method that has been previously reported [7]:

\section{Depositing buffer layer on FTO glass:}

Vacuum pump for spin-coater (MIKASA MS-A100) was turned on, speed was adjusted to $5000 \mathrm{rpm}$ and running time was set to 30 seconds. FTO glass was securely positioned in the center of spin coater rotating plate. The buffer layer solution of 2, 2-Iminodiethanol $(0.14 \mathrm{~g})$, Ethanol $(2.5 \mathrm{~mL})$, and Titanium Isopropoxide (TTIP) $(0.36 \mathrm{~g})$ was then delivered to the FTO glass by pipet until glass was fully covered (approximately 8 -12 drops). This buffer layer would strengthen the ability for deposited $\mathrm{TiO}_{2}$ particles to remain in contact with the solid surface of the FTO glass. The FTO surface was coated by placing the lid on the spin coater, and letting the spin coater run for the set speed and time. The FTO glass was then dried in an oven at $500^{\circ} \mathrm{C}$ for 60 minutes.

\section{$\mathrm{TiO}_{2}$ nanofluid preparation:}

Nanoparticles were mixed with Ethanol (99.9\%) to produce $15 \%$ by mass concentration of nanofluid. The nanoparticles were commercial PST-18NR ( $\sim 20 \mathrm{~nm})$ with Anatase crystal phase. Cap was screwed on and container was placed in a Conditioning Mixer (THINKY AR-250). Mixer was set for 2 minutes to obtain a homogenous nanofluid.

\section{$\mathrm{TiO}_{2}$ Deposition:}

Tape was carefully placed on opposite edges of the dried FTO glass. FTO glass was then carefully and securely lowered into the spin coater for the second time. The previously prepared nanofluid was then deposited onto prepared FTO glass by pipet until the glass was fully covered (approximately 8-12 drops). To fully coat the prepared FTO glass, the substrate was spin-coated at $1500 \mathrm{rpm}$ for 30 seconds. The sample was then dried by running the spin coater at $1000 \mathrm{rpm}$ for 60 seconds. After spin coating, the tape was removed from the FTO glass and the glass was then placed on a hot plate to dry at $120^{\circ} \mathrm{C}$.

\section{Sintering process:}

FTO glass with $\mathrm{TiO}_{2}$ particles deposited was placed in an electric oven to sinter the substrate. The temperature was increased to $325^{\circ} \mathrm{C}$ in $10 \mathrm{~min}$. and maintain for $5 \mathrm{~min}$., then increased to $375^{\circ} \mathrm{C}$ in $10 \mathrm{~min}$. and maintain for 5 minutes, followed by increasing the temperature to $450^{\circ} \mathrm{C}$ in $10 \mathrm{~min}$. and maintain for $5 \mathrm{~min}$. Lastly, the temperature was raised to $500^{\circ} \mathrm{C}$ in $10 \mathrm{~min}$. and maintain for $15 \mathrm{~min}$. The substrate was cooled to room temperature.

\section{$\mathrm{TiCl}_{4}$ treatment:}

In a very clean environment, the samples were placed inside the glass sample holder. The $\mathrm{TiCl}_{4}$ was massed on a scale, inside fume hood, in a graduated cylinder $(1.39 \mathrm{~g})$. Still under the fume hood, water was added to 
and mixed well with the $\mathrm{TiCl}_{4}(120 \mathrm{~mL})$. This mixture was then poured into the sample holders so that all of the samples were covered completely with the $\mathrm{TiCl}_{4}$ mixture. After the sample containers were placed in the oven, they were left to heat for 30 minutes at $60^{\circ} \mathrm{C}$. Once heating was completed, the liquid was poured out and the samples were washed thoroughly (about 3 times) with deionized water. After washing, samples were removed one at a time and washed individually with water then left to dry.

\section{Perovskite solution:}

First, the Perovskite solution was made in a controlled environment with low humidity and filled with Nitrogen. Dimethylformamide (DMF) and Dimethyl Sulfoxide (DMFO) were mixed 6:4 by volume. With CsI (0.0168 g), $\mathrm{PbI}_{2}$ (0.5441 g), Formamidinium Iodide (FAI) (0.1805), Methylammonium Bromide (MABr) $(0.0244 \mathrm{~g})$, and $\mathrm{PbBr}_{2}(0.0680 \mathrm{~g}), 1 \mathrm{~mL}$ of the DMF/DMFO solution was mixed to make the Perovskite solution. The Perovskite solution was then deposited on the treated FTO glass, in the same environment that the solution was prepared, using a specific process. The FTO glass with $\mathrm{TiO}_{2}$ particles $\left(\mathrm{FTO}-\mathrm{TiO}_{2}\right)$ was obtained from a hot plate where the glass was kept at $80^{\circ} \mathrm{C}$ for $60 \mathrm{~min}$. prior to the deposition process to reduce amount of moisture. Once the treated FTO glass was ready it was placed on a hot plate to heat for $10 \mathrm{~min}$. at $55^{\circ} \mathrm{C}$. The $\mathrm{FTO}^{-\mathrm{TiO}_{2}}$ glass was then carefully placed on the rotating plate of the spin coater. The Perovskite solution was deposited on the glass by a pipet until glass was fully coated (8-12 drops) and left to calm for 70 seconds. The substrate was then spin-coated at $3500 \mathrm{rpm}$ for 30 seconds after Anisole $(0.3 \mathrm{~mL})$ was dropped onto glass. Once the coating was complete, the $\mathrm{FTO}^{-\mathrm{TiO}_{2}}$ glass was moved from the spin coater to a hot plate where it was heated for $10 \mathrm{~min}$. at $155^{\circ} \mathrm{C}$ then allowed to cool to room temperature.

\section{Spiro-OMeTAD solution (Hole transport layer):}

To make the Spiro-OMeTAD solution, Spiro-OMeTAD $(0.0528 \mathrm{~g})$ was mixed with Chlorobenzene $(0.64 \mathrm{~mL})$, 4-tert-Butylpyridine (TBP) $(14.4 \mu \mathrm{L})$, and a LiTFSI $(0.500 \mathrm{~g})$ in Acetonitrile $(1 \mathrm{~mL})$ mixture. After preparing the mixture, the FTO- $\mathrm{TiO}_{2}$ glass with previously deposited Perovskite solution was placed on the spin coater, in the same environment for Perovskite solution deposition, where 2 drops of the Spiro-OMeTAD solution is deposited on the middle of the glass. The substrate was then spin-coated for 30 seconds at $3000 \mathrm{rpm}$. After coating, the $\mathrm{FTO}-\mathrm{TiO}_{2}$ glass was dried one night in air.

\section{Making a Counter Electrode:}

The previously prepared FTO glass was attached to a metal mask using tape to prepare the substrate for gold deposition. These glass/mask pieces were then taped to the lid of the Thermal Evaporation Deposition Machine (Figure 1a and Figure 2) with the glass against the lid. After all samples were in place, the plate arm was swung over to cover the samples. The edge of the chamber was then greased for a good seal and the lid was gently lowered and latched tightly. To start this machine the vacuum was first turned on, the pressure was stabilized, and finally the pump was turned on. The amount of gold wire for assembling the perovskite solar cell was $0.11 \mathrm{~g}, 0.14 \mathrm{~g}$, and $0.19 \mathrm{~g}$, respectively. For $0.11 \mathrm{~g}, 0.14 \mathrm{~g}$ conditions, one piece of gold wire was used, whereas the gold wire was cut into three pieces for the $0.19 \mathrm{~g}$ condition. The gold was left to melt inside the Thermal Evaporation Deposition Machine where the melting temperature was tuned by adjusting the current. In this case, the current increased in two steps. In the first step, the current was $30 \mathrm{Amp}$ to remove the gold impurities and in the second step, current increased to $70 \mathrm{Amp}$ to melt down the gold in the scoop. The electric heater is inside a stainless-steel chamber and the pressure inside the chamber is controlled by vacuum pump. The gold deposits at $2 \times 10^{-3} \mathrm{~Pa}$ for 20-30 seconds. Once gold was melted inside the scoop, the current was turned off. The main valve was closed and then the machine was turned off. This machine allowed for the melted gold to be deposited through the holes of the masks covering the FTO glass (Figure 1b), the thickness of this deposition can be changed based on how much gold is in the scoop. 
(a)

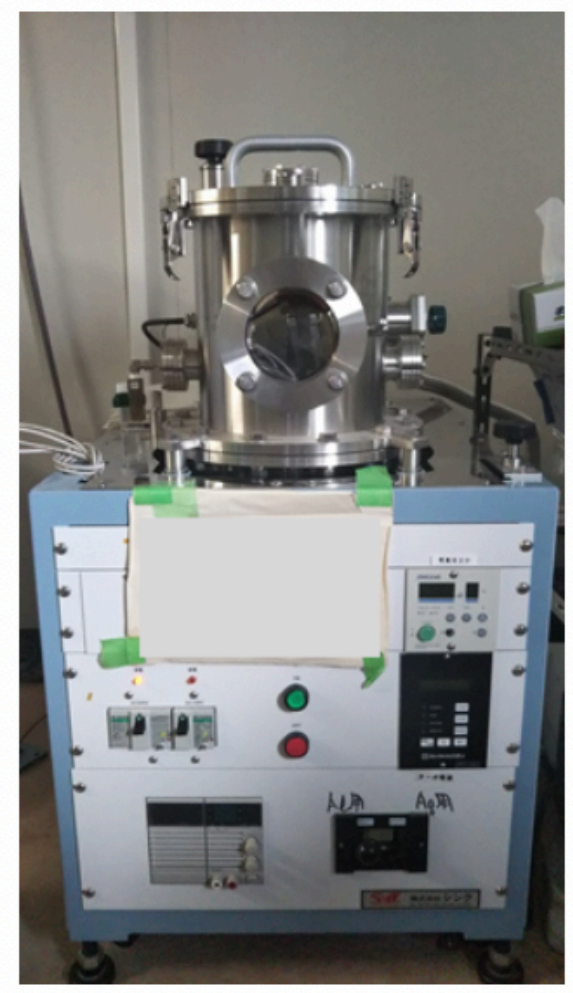

(b)

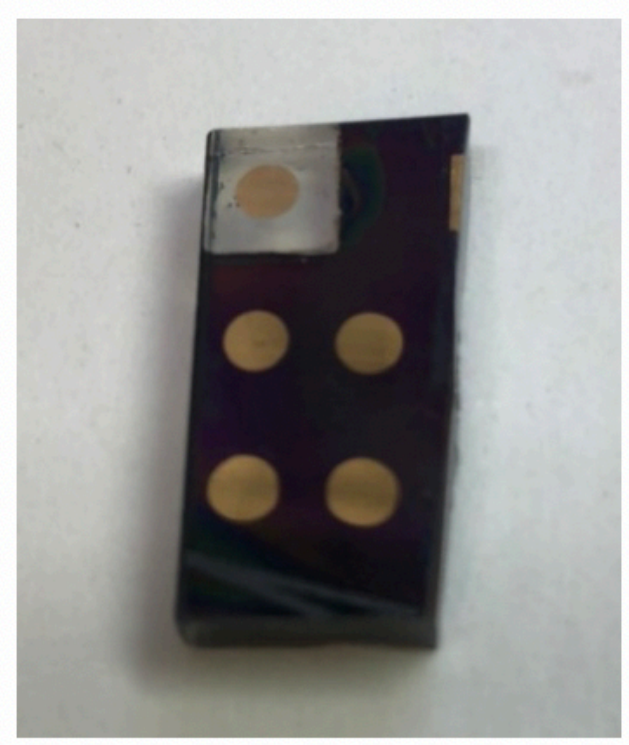

Fig. 1 Thermal Evaporator machine (a) and perovskite solar cell (b).

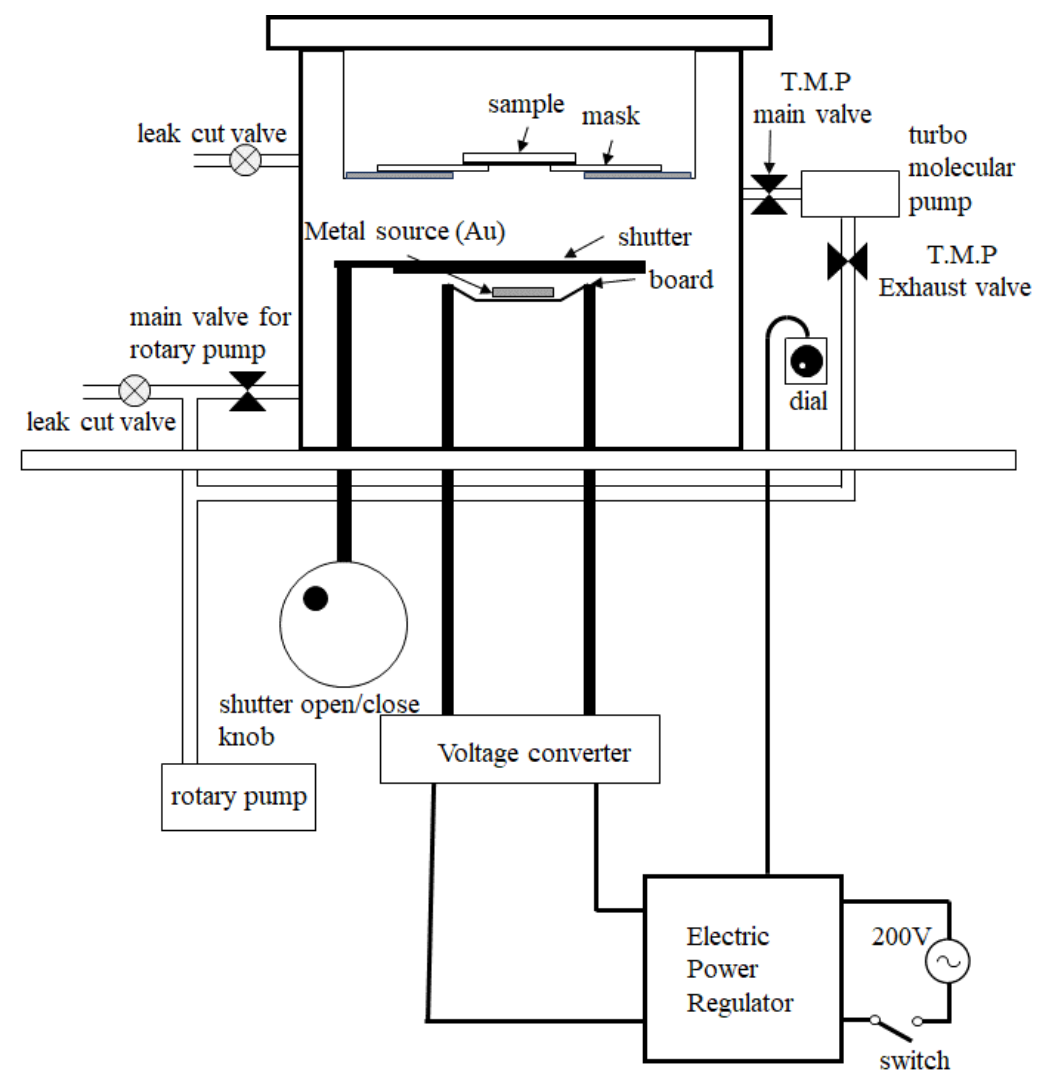

Fig. 2 A configuration of the gold evaporation apparatus used in the assembly of Perovskite solar cell. 


\subsection{Measurement of Current-Voltage Curves}

After the counter electrode was made the I-V curves of these cells were tested by a Solar Simulator (YSS-80A), Figure 3. The sample was connected to the Solar Simulator with probes where the gold was deposited and placed under the light of the machine. A potentiostat (Hokuto Denko) equipped with the solar simulator created a current vs voltage graph and that data was collected. The measurement was carried out under 1 sun light condition. The active area of device was set to $0.07 \mathrm{~cm}^{2}$.

(a)

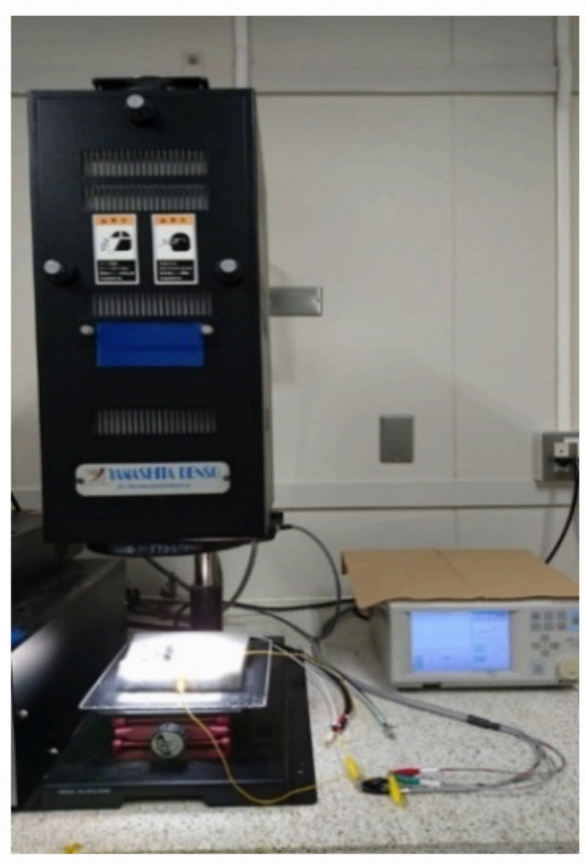

(b)

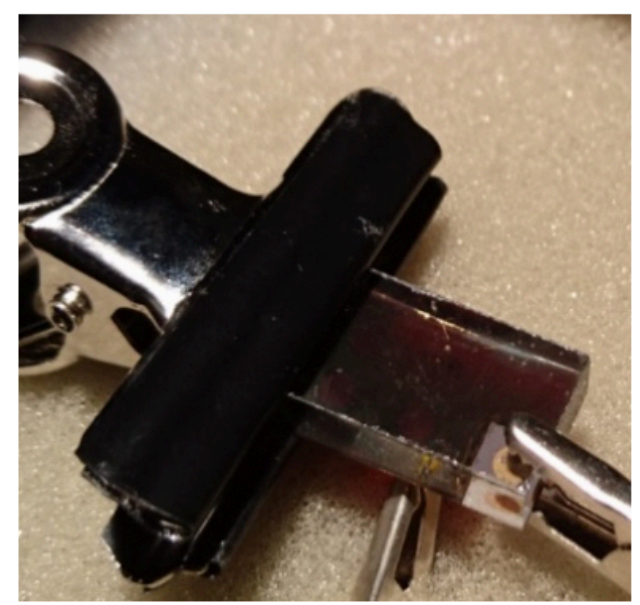

Fig. 3 (a) Measurement of efficiency of Perovskite solar cell using a simulated solar light (1 sun) (b) Perovskite solar cell.

\subsection{Structure analysis of device}

The cross-sectional image of device was captured by scanning electron microscope (S-4300) after gold evaporation.

\section{RESULTS AND DISCUSSIONS}

Integrated structure of $\mathrm{TiO}_{2}$, light-absorbing perovskite, spiro-OMeTAD (hole-transport material), and gold cathode on the FTO substrate was observed using Scanning Electron Microscopy (SEM), Figure 4. Identification of gold and other elements was in progress using Energy Dispersive X-ray Spectroscopy (EDX) measurement.

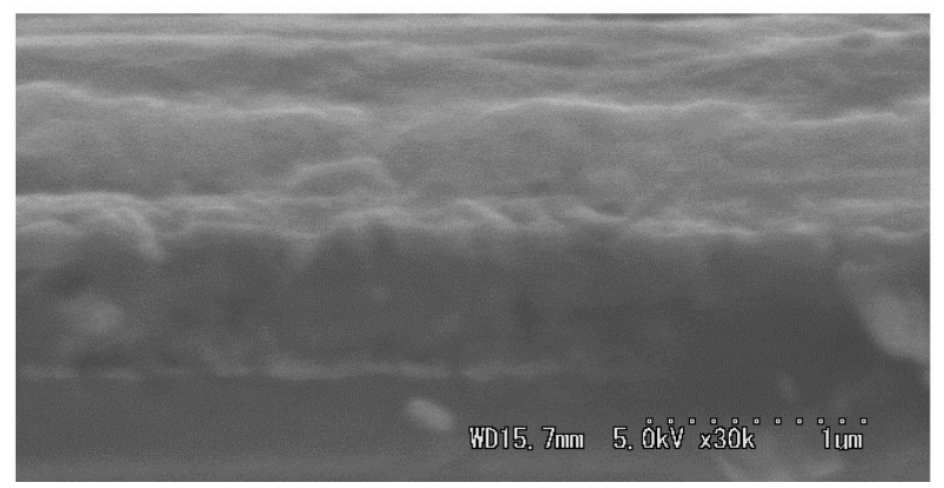


Fig. 4 Cross-sectional SEM image of the perovskite solar cell.

Table 1 shows the photovoltaic parameters of short-circuit current density $\left(\mathrm{J}_{\mathrm{sc}}\right)$, open-circuit voltage $\left(\mathrm{V}_{\mathrm{oc}}\right), \mathrm{FF}$, and photon-to-light conversion efficiency (PCE) of the Perovskite Solar Cell changing the amount of evaporated $\mathrm{Au}$. The amount of gold $(\sim 0.1 \mathrm{~g})$ produced a very thin gold layer on the Spiro-Ometad layer, therefore the device could not be used for I-V measurement. We found that PCE of $\sim 15 \%$ can be observed when the amount of gold was around $0.11 \mathrm{~g}$ and $0.14 \mathrm{~g}$. The efficiency decreased when $0.19 \mathrm{~g}$ of gold was used. It was thought that three pieces of gold wire for $0.19 \mathrm{~g}$ could be easily evaporated. One of the reasons for the decreased performance is the thermal decomposition of the organic hole-transport layer by the efficient infiltration of gold, worsening the device performance. The results found in our work indicated the importance of optimizing a vacuum process i.e. gold evaporation condition for the assembly of perovskite solar cells. Further optimization of gold evaporation is in progress to enhance the performance of solar cells.

Table 1 The effect of evaporated Au amount (a-c) on the performance of Perovskite solar cell.

(a) $0.11 \mathrm{~g} \mathrm{Au}$

\begin{tabular}{c|r|r|r|}
\hline PCE & $J_{\text {sc }}\left(\mathrm{mA}^{\left.-\mathrm{cm}^{2}\right)}\right.$ & $V_{\text {oc }}(\mathrm{V})$ & FF \\
\hline $14.6 \%$ & 21.4 & 1.05 & 0.65 \\
\hline
\end{tabular}

(b) $0.14 \mathrm{~g} \mathrm{Au}$

\begin{tabular}{|c|r|c|c|}
\hline PCE & $J_{\mathrm{sc}}\left(\mathrm{mA} / \mathrm{cm}^{2}\right)$ & $V_{\text {oc }}(\mathrm{V})$ & FF \\
\hline $14.5 \%$ & 21.6 & 1.03 & 0.65 \\
\hline
\end{tabular}

(c) $0.19 \mathrm{~g} \mathrm{Au}$

\begin{tabular}{|r|r|r|r|}
\hline PCE & $J_{\mathrm{sc}}\left(\mathrm{mA} / \mathrm{cm}^{2}\right)$ & $V_{\mathrm{oc}}(\mathrm{V})$ & FF \\
\hline $13.3 \%$ & 21.5 & 1.00 & 0.62 \\
\hline
\end{tabular}

\section{CONCLUSION}

A manmade device was applied to control thermal evaporation of the Au layer in Perovskite Solar Cell (PSC). Au was used as a cathode material depositing on the hole transport material (Spiro-OMeTAD). The amount of $\mathrm{Au}$ was varied, using the PSC consisting of conductive FTO glass/buffer layer- $\mathrm{TiO}_{2} /$ nanocrystalline$\mathrm{TiO}_{2} / \mathrm{Perovskite} / \mathrm{Spiro}-\mathrm{OMeTAD} / \mathrm{Au}$. The amount of evaporated $\mathrm{Au}$ in the cathode deposition process was one of the keys to optimize the performance of Perovskite Solar Cell.

\section{ACKNOWLEDGMENT}

This work was supported by the Koshiyama Research Grant and Illinois Space Grant Consortium, USA.

\section{REFERENCES}

[1] Jena, A.-K., Kulkarni. A, Miyasaka, T., "Halide Perovskite Photovoltaics: Background, Status, and Future Prospects", Chem. Rev., 119(5), pp. 3036-3103, (2019).

[2] Kojima, A., Teshima, K., Shirai, Y., Miyasaka, T., “Organometal Halide Perovskites as Visible-Light Sensitizers for Photovoltaic Cells", J. Am. Chem. Soc., 131(17), pp. 6050-6051, (2009).

[3] Burschka, J., Pellet, N., Moon, S.-J., Humphry-Baker, R., Nazeeruddin M.-K., Grätzel, M., "Sequential deposition as a route to high-performance perovskite-sensitized solar cells"' Nature, 499, pp. 316-319, (2013).

[4] Lee, M.-M., Teuscher. J., Miyasaka, T., Murakami, T.-N., Snaith, H.-J., "Efficient hybrid solar cells based on meso-superstructured organometal halide perovskites"'Science, 338, pp. 643-647, (2012). 
[5] Liang, J., Zhao, P., Wang, C., Wang, Y., Hu, Y., Zhu, G., Ma, L., Liu, J., Jin, Z., “CsPb ${ }_{0.9} \mathrm{Sn}_{0.1} \mathrm{IBr}_{2}$ Based All-Inorganic Perovskite Solar Cells with Exceptional Efficiency and Stabilit", J. Am. Chem. Soc., 139(40), pp. 14009-14012, (2017).

[6] Zhang, G., Hawks, S.-A., Ngo, C., Schelhas, L.-T., Scholes, D. T., Kang, H., Aguirre, J. C., Tolbert, S.-H. Schwarts, B.-J., "Extensive Penetration of Evaporated Electrode Metals into Fullerene Films: Intercalated Metal Nanostructures and Influence on Device Architecture", ACS Appl. Mater. Interfaces, 7, pp. 25247-25258, (2015).

[7] Zhao, P., Kim. Kim, B.-J., Ren, X., Lee, D.-G., Bang, G.-J., Jeon, J.-B., Kim, W.-B., Jung, H.-S., “Antisolvent With An Ultrawide Processing Window For The One-Step Fabrication of Efficient And Large-Area Perovskite Solar Cells", Adv. Mater, 30, 1802763, (2018). 